\title{
Prosthetic rehabilitation for patient with hemi-maxillectomy: Obturator combined with a hybrid telescopic double crown using friction pin
}

\author{
Jeong-Gyo Seo, Jin-Hyun Cho* \\ Department of Prosthodontics, School of Dentistry, Kyungpook National University, Daegu, Republic of Korea
}

When oral cancer develops in the maxilla, oro-nasal communication occurs after surgical treatment including removal of the primary site. Restoration through an obturator is necessary to prevent food from storing due to non-oral opening, and to ensure proper pronunciation and aesthetic restoration. In this case, the patient was treated with right hemi-maxillectomy due to oral cancer and has residual abutment and poor periodontal support due to the effect of head and neck radiotherapy. The obturator was treated with a hybrid telescopic double crown denture. Reporting a successful prognosis in 18 months of follow-up. (J Dent Rehabil Appl Sci 2018;34(4):317-23)

Key words: oral cancer; maxillecotmy; telescopic double crown removable partial denture; friction pin

\begin{abstract}
서론
2017년에 발표된 중앙암등록본부 자료에 의하면 2015 년 한국에서 214,701 건의 암이 발생했는데, 그 중 구강암 은 남녀를 합쳐서 654 건으로 전체 암 발생의 $0.3 \%$ 를 차 지하였다. ${ }^{1}$ 구강암의 외과적 치료는 환자에게 안모 재건 및 사회적 활동 등의 문제뿐 아니라 저작, 연하, 발음 등 과 같은 구강악안면부가 가지는 고유 기능의 결손을 동 반하게 된다. 두경부 방사선 치료 및 항암 요법 후의 악 안면부 재건에 있어 보철적 수복은 구강의 심미와 기능 적 개선을 가능하게 한다. ${ }^{2-4}$ 특히 상악에 구강암이 발생 한 경우 원발 부위의 외과적 제거 후 비구강 개통(oronasal communication)이 발생하게 되며, 음식물 섭취 시 구강에서 상악동 및 비강 내로 음식물의 유입을 막고 원 활한 발음을 위해서는 구강 폐색장치(obturator)로 보철

*Correspondence to: Jin-Hyun Cho

Professor, Department of Prosthodontics, School of Dentistry, Kyungpook National University, 2177, Dalgubeol-daero, Jung-gu, Daegu, 41940, Republic of Korea Tel: +82-53-600-7651, Fax: +82-53-427-0778, E-mail: prosth95@knu.ac.kr Received: July 29, 2018/Last Revision: August 23, 2018/Accepted: September 9 , 2018
\end{abstract}

적 재건을 하는 것이 필수적이다. ${ }^{5}$ 본 증례는 74 세 여자 환자로 구강암으로 인해 우측 상악 편측절제술(hemimaxillectomy)를 시행였고, 두경부 방사선 치료의 영향 으로 인해 상악 좌측 구치부 고정성 보철물의 지대치는 치경부 우식으로 인한 잔존 치근 상태로 불량한 치주 지 지를 보였다. 방사선 치료로 잔존 치근은 발치가 불가능 한 상태로 구강암 수술을 한 병원에서는 추 후 모든 잔 존치를 발치 하는 것을 추천하였다. 하지만 남아있는 소 수의 지대치는 상악 양 중절치와 제2대구치로, 이를 살 려 보철물의 삽입 철거로 설정 및 치축 방향으로의 이차 적 고정(secondary splinting) 효과를 갖는 구강 폐색장치 를 제작하기 위해 하이브리드형 텔레스코픽 이중관 의치 (hybrid telescopic double crown denture)로 수복하였다. 방사선 치료를 병행하면서도 18 개월 간 성공적인 예후를 보여 이를 보고하고자 한다.

Copyright@ 2018 The Korean Academy of Stomatognathic Function and Occlusion. (c) It is identical to Creative Commons Non-Commercial License. 


\section{증례보고}

본 증례의 환자는 74 세 여자 환자로 1 년 전 상악동암 으로 인해 우측 상악골 편측 절제술을 받은 후 식사가 힘 들다는 주소로 내원하였다. 수술 완료 후 치료 받았던 임 시 구강 폐쇄기는 잘 맞지 않아 음식물이 결손부 내로 유 입 되고 점막 통증을 야기하여 착용하지 않는 상태였다. 초진 당시 두경부 방사선 치료를 병행하고 있었으며, 구 강 내 임상 검사 및 파노라마 방사선 사진 상 상악 좌측 고정성 보철물의 지대치 중 \#22, 23의 치경부 우식으로 인해 보철물 하방으로 잔존 치근이 존재하는 상태였고, 심한 치주염도 관찰되었다(Fig. 1).

상악은 전반적인 치주상태가 불량하며, 두경부 방사선 치료로 인해 발치 및 임플란트 식립이 어려운 상태임을 감안하여 잔존 지대치를 이용한 가철성 의치로 치료계획 을 수립하였다. 상악 우측 결손부 및 좌측의 저작기능 회 복을 위해 \#11, 21, 27를 지대치로 하여 마찰핀(friction pin)을 부가적인 유지장치로 하는 하이브리드형 텔레스 코픽 이중관 의치(Hybrid telescopic double crown denture) 형태의 구강폐색장치로 수립하였다. ${ }^{5} \# 22,23$ 의 잔 존치근은 두경부 방사선 치료로 발치가 불가능하여 남겨 두기로 하였다. 하악은 우측 구치부가 외팔보(cantilever) 형태로 후방으로 기울어진 교합평면을 보였으나 지대치 $\# 44,45$ 가 건전한 상태였으며, 우측으로는 상악 보철물 과 교합 되지 않도록 계획 하였다.

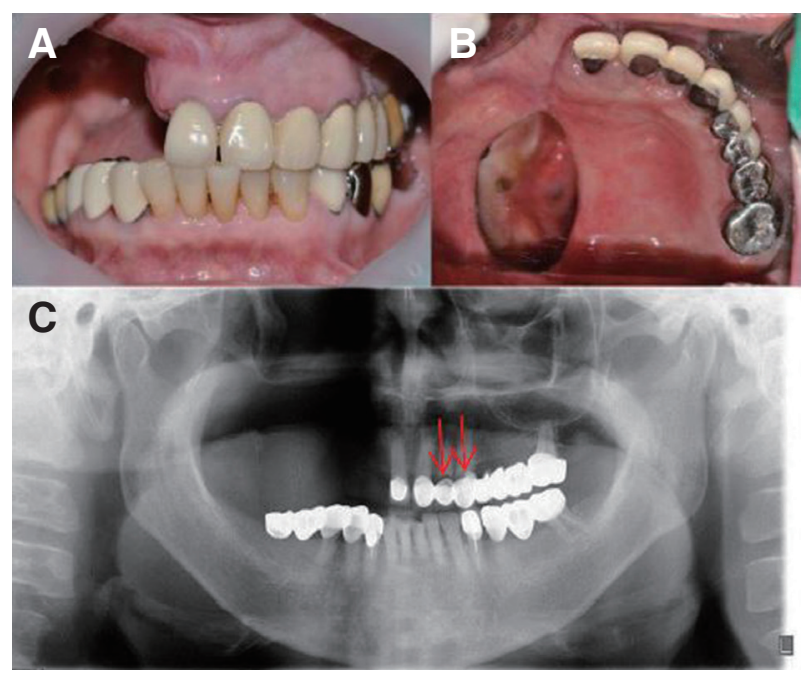

Fig. 1. Initial intraoral photograph and panoramic radiograph. (A) Frontal view, (B) Occlusal view, (C) Panoramic radiograph. Arrow: cervical caries on \#22, 23.
상악은 알지네이트(Alginoplast Fast Set, Kulzer GmbH, Hanau, Germany) 예비 인상을 채득하여 개인 트레이를 제작하였으며, 지대치 인상 채득 전 기존 보철물의 제거 및 \#11, 21, 27 지대치의 우식 치료를 시행하였다(Fig. 2). \#11, 21, 27 지대치를 재형성 하고 미리 제작된 개인 트 레이를 통해 실리콘 인상재(Aquasil LV, Dentsply, Milford, USA)로 이중관 의치의 내관 제작을 위한 지대치 인 상을 채득하였다(Fig. 3).

상악 최종 모형 상에서 내관 제작을 위한 왁스업 후 \#11, 21의 원심면과 \#27의 근심면에 마찰핀(friction pin)을 위한 공간을 부여하였다. 내관의 축벽 경사는 $2^{\circ}$ 로 설정하고 외관의 수직적 움직임을 허용하지 않는 chamfer margin을 형성 하였으며 비귀금속 합금으로 내 관(VeraBond 2V, Albadent, Fair field, USA)을 주조하였 다(Fig. 4).

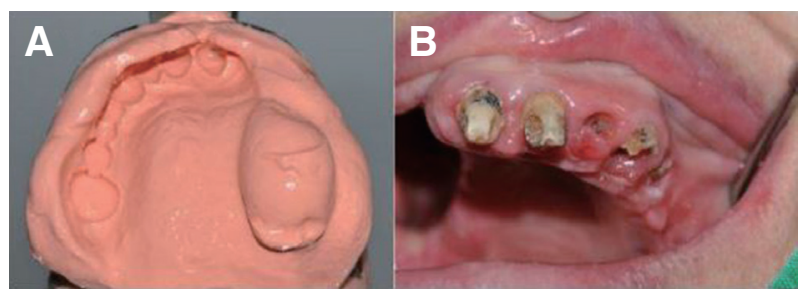

Fig. 2. Pre-prosthodontic treatment of abutments. (A) Maxillary alginate impression for individual tray, (B) Caries were removed.
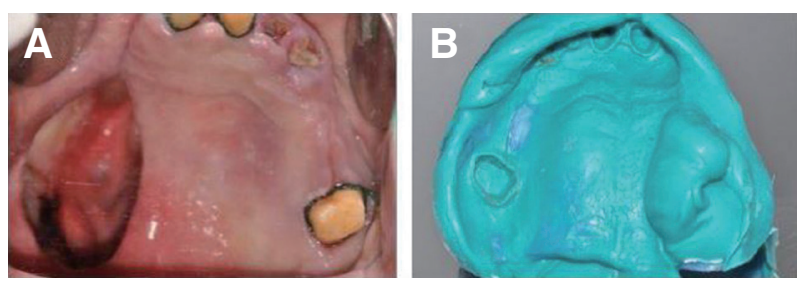

Fig. 3. Impression of maxillary abutments. (A) Preparation of abutments, (B) Impression taking for inner crowns.
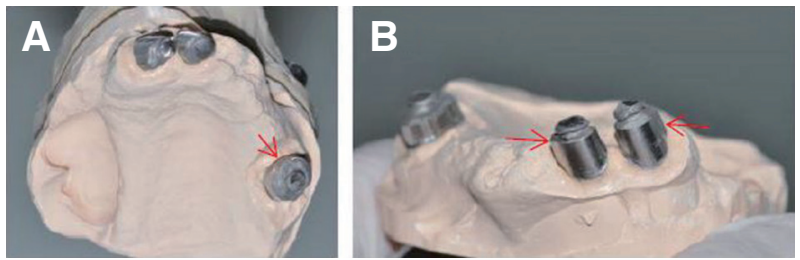

Fig. 4. Inner crowns of double crown denture (A) Occlusal view, (B) Inner crown of \#11, 21 abutments. Arrow: space for friction pin. 
내관을 구강 내에서 패턴 레진(Pattern resin, GC, Tokyo, Japan) 고정하였으며, 개인 트레이의 지대치 부위 를 개방하여 인상 채득 시 지대치의 움직임을 최소로 하 였다. 실리콘 변연 형성 재료로(Aquasil Rigid, Dentsply) one-step border molding을 시행하였으며, 실리콘 인상 재(Aquasil LV, Dentsply)로 픽업(pick-up) 인상을 채득 하였다(Fig. 5).
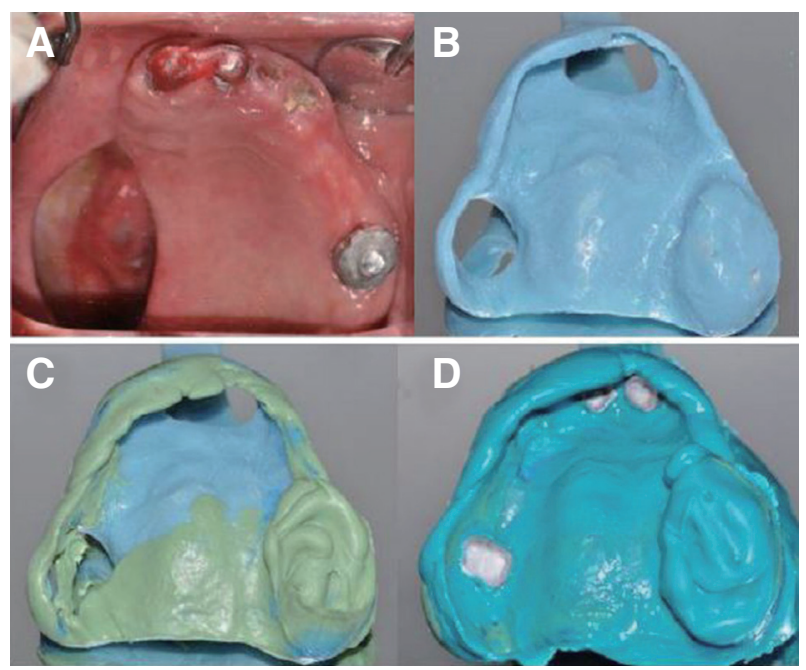

Fig. 5. Maxillary impression procedure. (A) Inner crowns were splinted, (B) Open tray modification, (C) After onestep border molding, (D) Pick up impression of inner crown.
상악 주모형 상에서 기록상 및 교합제를 제작하였으 며, 내관과 함께 구강 내 시적 하였다. 수직 고경 및 중 심위 결정을 위해 실리콘 교합 인기재(Cresil, Creden, Daegu, Korea)로 교합 관계를 인기하고 안궁이전을 시 행하였다(Fig. 6).

상악 이중관 의치는 먼저 외관을 내관 위에서 내관과 동일한 금속으로 제작을 하고, 주연결자(Major connector)를 완전구개판(Full palatal plate) 형태로 제작하여 외관과 레이져 용접(laser welding)을 하였다. 내관과 외 관 사이 유지력을 위해 마찰핀은 약 $0.8 \mathrm{~mm}$ 의 공간을 방 전 가공(spark erosion)을 통하여 위치시켰고, 레이저 용 접과 샌드블라스팅(sandblasting)을 시행하였다. ${ }^{6}$ 이중관 의치 외관 및 금속 구조물(Metal framework)이 포함된 납의치를 구강 내 시적 후 수직고경 및 중심위를 재 확인 하였다(Fig. 7). 상악 의치를 온성 경화하고 경질레진(Sinfony, 3M ESPE, Seefeld, Germany)으로 외관을 완성하 였다. 완성된 상악 이중관 의치의 조정을 시행하고 연마 후 최종 장착하였다(Fig. 8). 최종 보철물 장착 후 18 개월 경과 관찰 시 구강 내 검사 및 방사선 사진 평가에서 지대 치 및 이중관 의치가 안정적으로 기능하는 것을 확인 할 수 있었다. 두경부 방사선 치료의 영향으로 \#22, 23은 추 후 발치를 시행 할 예정이다(Fig. 9).

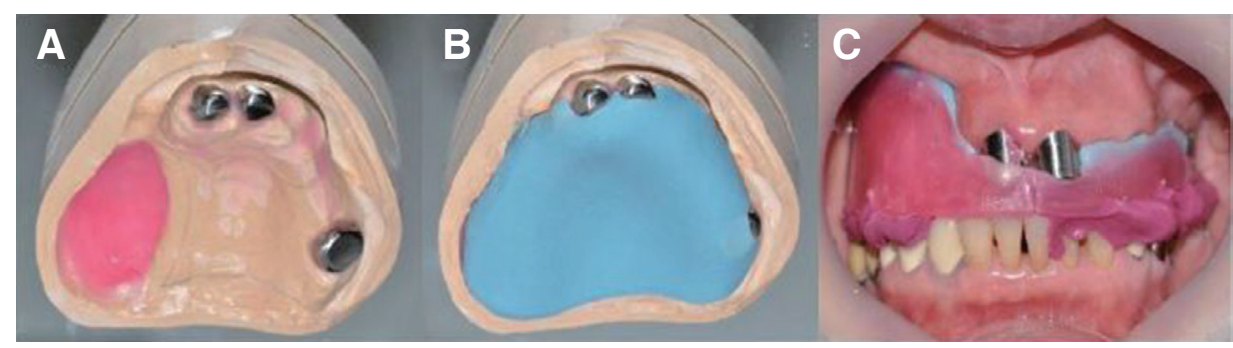

Fig. 6. VD/CR recording. (A) Maxillary master cast, (B) Recording base fabrication, (C) CR Bite registration.
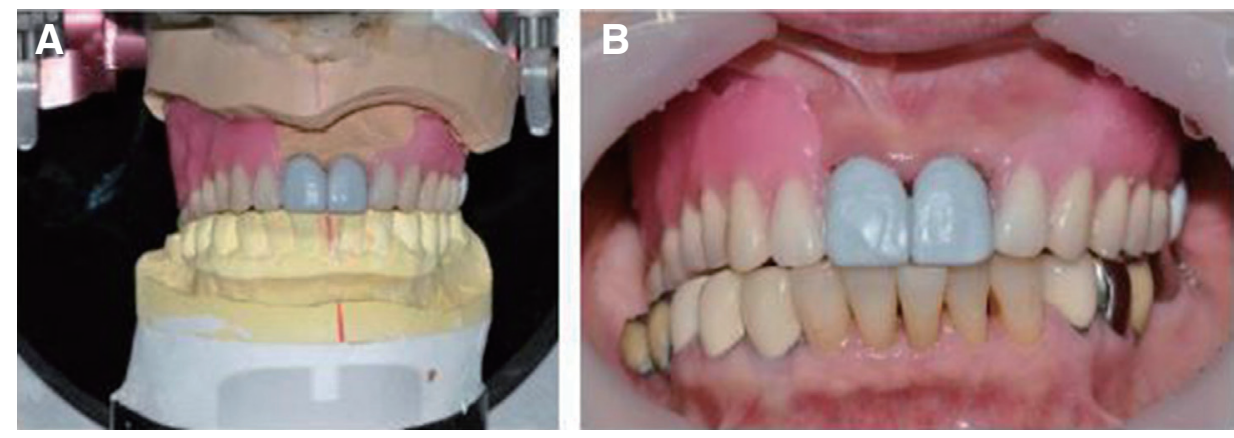

Fig. 7. Wax denture. (A) Wax denture in Articulator, (B) Wax denture try in. 

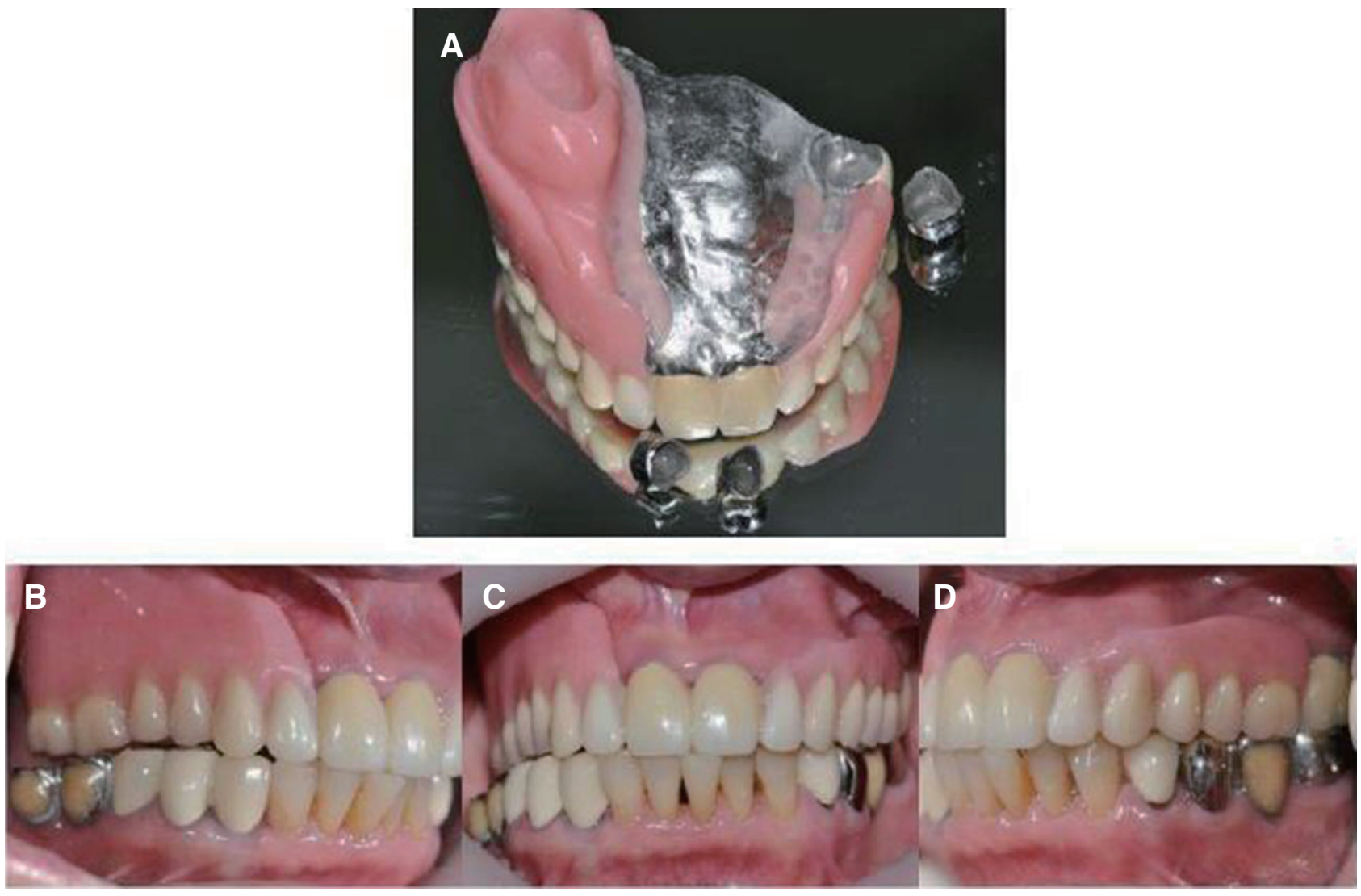

Fig. 8. Definitive prosthesis. (A) Inner crown and double crown RPD, (B) Right buccal view, (C) Frontal view, (D) Left buccal view.
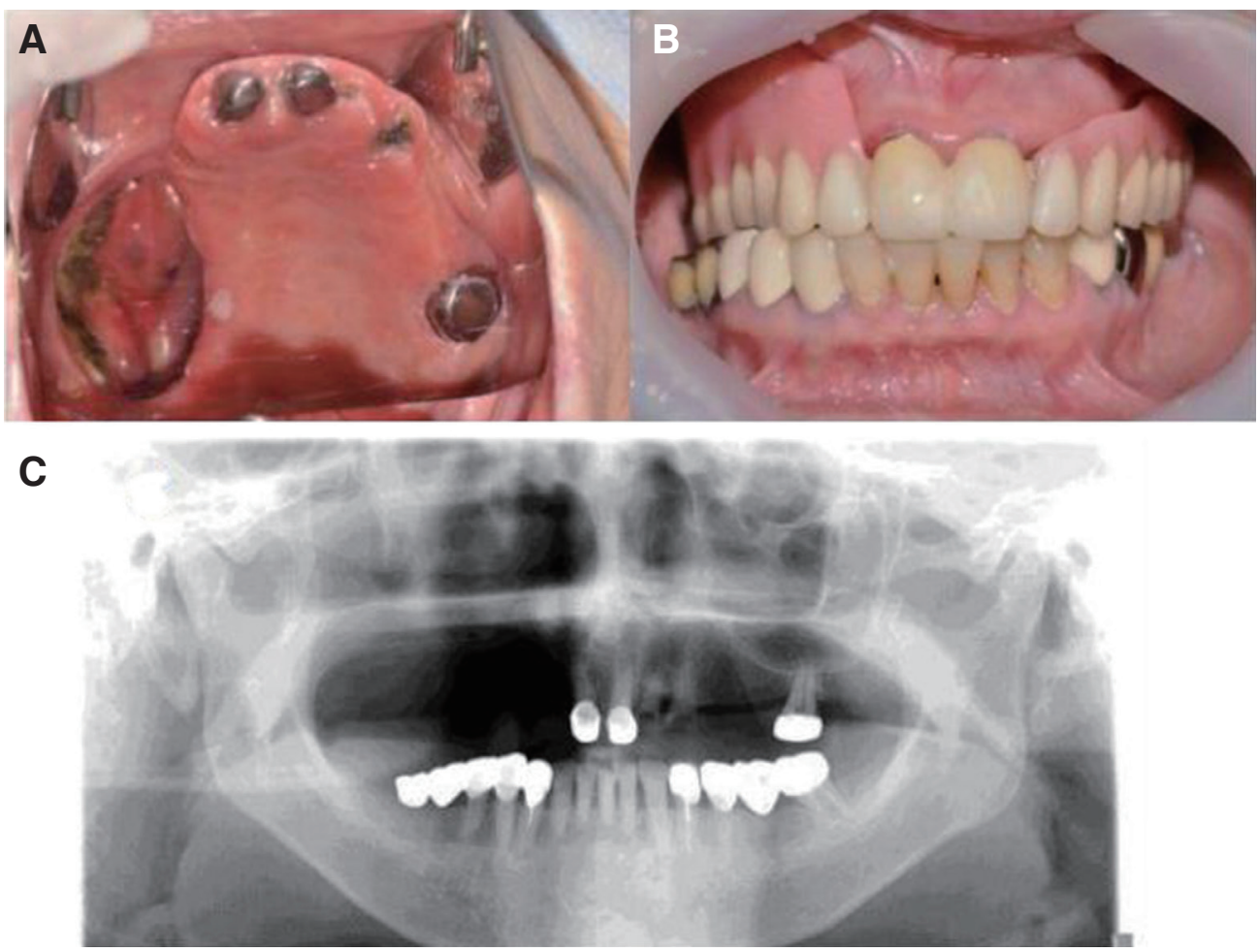

Fig. 9. 18 month follow up check after delivery. (A) Occlusal view of inner crown, (B) Frontal view with denture seated, (C) Panoramic radiograph. 


\section{고찰}

구강암 수술로 인해 비구강 개통(oro-nasal communication)이 발생한 환자에서 구강 폐색장치는 발음, 저작 기능, 연하 및 안모 형성에 있어 필수적인 역할을 담당하 게 된다. Aramany classification 에 따르면 본 증례의 결 손은 편측의 상악골이 절제된 형태인 class II로 분류 할 수 있으며, 치주적으로 양호하지 않은 소수의 잔존 자연 치만 남은 상태였다. Aramany의 분류법에 따라 전통적 인 클라스프 형태의 구강 폐쇄기로 디자인 할 경우 케네 디 2급(Kenndy class II) 형태의 국소의치 디자인이 가능 하지만, ${ }^{8}$ 소구치부의 부재로 간접 유지장치 설정이 불가 능하고 특히 소수 잔존치가 남아 있는 경우에는 전통적 인 클라스프형 국소의치로 치료하는 것은 장기적인 예후 를 보장하기 힘들다. 방사선치료를 지속적으로 받고 있 기 때문에 치주치료나 발치를 할 수 없는 상황이기 때문 에 지속적인 검진과 구강위생이 중요하다. 이중관 의치 의 특징인 저작력이 치아의 장축으로 향하고, 내외관의 마진 부위가 지점(fulcrum)이 되기 때문에 치아의 회전축 (Axis of rotation)에서의 거리가 짧은 지렛대(lever arm) 를 가지기 때문에 예후가 클라스프형 국소의치보다 우 수하다. ${ }^{9}$ 또한 가철성 보철물이 지대치와 견고하게 연결 되기 때문에 지대치에 응력이 많이 가지만 측방하중을 줄이고 수직적 하중을 증가시켜 응력 분산에 있어 긍정 적인 효과와 더불어 의치에 의한 2 차 고정효과(secondary splinting effect)로 인해 장기적인 지대치의 성공률 을 높일 수 있다..$^{10-12}$ Anil 등에 따른 증례 보고에서도 편 측 상악골 절제 술 후 텔레스코픽 이중관 의치(telescopic double crown denture)로 수복한 증례에서 구강 폐쇄기 의 성공적인 유지 및 안정요소 부여와 기능에 대해 언급 한 바 있다. ${ }^{13}$ 하지만 마찰핀을 이용한 하이브리드형 텔 레스코픽 이중관 의치는 장기간 사용 시 탈착력에 의한 지대치에 접착된 내관의 탈락이나 응력 집중에 따른 외 관 경질 레진의 파절과 같은 합병증이 주로 발생하게 되 며, 내,외관을 위한 공간 형성에 따른 지대치 삭제량이 증 가할 수 있는 한계점이 존재한다. 증례에서 방사선 치료 가 완료 되어 발치가 가능하게 되면 \#22, 23 발치 후 의 치 이장과 정기적인 검사를 병행하게 된다면 안정적인 예 후를 기대할 수 있다.
결론

구강암으로 인해 편측 상악골 절제와 방사선 치료로 인해 소수의 잔존 지대치가 남은 환자에게 있어 비귀금 속을 이용한 하이브리드형 텔레스코픽 이중관 의치(hybrid telescopic double denture)으로 구강 폐쇄기를 제작 하였다. 18 개월 간의 정기적 검진에서 방사선 치료의 영 향에도 불구하고 지대치의 양호한 치주 및 구강위생 관 리 상태를 보였다. 본 증례를 통해 이중관 의치를 이용한 구강 폐쇄기는 발음, 심미, 저작 기능에 더해 의치의 유지, 지지, 안정요소를 모두 고려하여 수복된 적절한 치료법임 을 확인 할 수 있었다. 앞으로 좀 더 장기적인 관점에서 효 용성을 입증하기 위해 지속적 관찰이 필요할 것이다.

\section{Acknowlegments}

This research was supported by Kyungpook National University Research Fund, 2016.

\section{ORCID}

Jin-Hyun Cho https://orcid.org/0000-0002-2453-9372

Jeong-Gyo Seo https://orcid.org/0000-0003-2322-5715

\section{References}

1. National Cancer Information Center. Available from: https://www.cancer.go.kr/lay1/program/S1T211C223/cancer/view.do?cancer_ seq $=3461 \&$ menu_seq=3466 (updated 2018 Aug 15).

2. Rogers SN, Lowe D, McNally D, Brown JS, Vaughan ED. Health-related quality of life of after maxillectomy: a comparison between prosthetic obturation and free flap. J Oral Maxillofac Surg 2003;61:174-81.

3. Minsley GE, Warren DW, Hinton V. Physiologic responses to maxillary resection and subsequent obturation. J Prosthet Dent 1987;57:338-44.

4. Devlin H, Barker GR. Prosthetic rehabilitation of the edentulous patient requiring a partial maxillectomy. J Prosthet Dent 1992;67:223-7.

5. Keyf F. Obturator prostheses for hemimaxillectomy patients. J Oral Rehabil 2001;28:821-9.

6. Weber H, Frank G. Spark erosion procedure: a 
method for extensive combined fixed and removable prosthodontic care. J Prosthet Dent 1993;69:222-7.

7. Aramany MA. Basic principles of obturator design for partially edentulous patients. Part I: classification. J Prosthet Dent 1978;40:554-7.

8. Aramany MA. Basic principles of obturator design for partially edentulous patients. Part II: Design principles. J Prosthet Dent 1978;40:656-62.

9. Breitman JB. Nakamura S, Freedman AL, Yalisove IL. Telescopic retainers: an old or new solution? A second chance to have normal dental function. J Prosthodont 2012;21:79-83.

10. Wenz HJ, Hertrampf K, Lehmann KM. Clinical longevity of removable partial dentures retained by telescopic crowns: outcome of the double crown with clearance fit. Int J Prosthodont 2001;14:207-13.

11. Widbom T, Löfquist L, Widbom C, Söderfeldt B, Kronström M. Tooth-supported telescopic crown-retained dentures: an up to 9-year retrospective clinical follow-up study. Int J Prosthodont 2004;17:29-34.

12. Ishida K, Nogawa T, Takayama Y, Saito M, Yokoyama A. Prognosis of double crown-retained removable dental prostheses compared with claspretained removable dental prostheses: A retrospective study. J Prosthodont Res 2017;61:268-275.

13. Sethuram AK, Sahoo N, Sandhu H, Radhakrishnan V. Rehabilitation of a maxillectomy case with telescopic crowns: a case report. J Indian Prosthodont Soc 2013;13:236-9. 


\section{편측 절제된 상악골 환자에서 하이브리드 텔레스코픽 이중관 의치를 이용한 구강 폐색기 수복 증례}

서정교, 조진현*

경북대학교 치과대학 치과보철학교실

구강암이 상악에 발생하게 되면 원발 부위의 제거를 포함한 외과적 처치 후 비구강 개통(oro-nasal communication)이 발생하게 된다. 비구강 개통으로 인한 음식물의 저류를 막고 및 원할한 발음 및 심미적 회복을 위해서는 구강 폐색장치 (Obturator)를 통한 수복이 필요하다. 본 증례에서는 구강암으로 인해 우측 상악 편측절제술(hemi-maxillectomy) 시행하 고 두경부 방사선 치료의 영향으로 인해 잔존 지대치의 우식과 불량한 치주지지를 보이는 환자에서 구강폐색장치(obturator)를 하이브리드형 이중관의치(hybrid telescopic double crown denture)로 수복하였다. 18 개월 간 경과관찰에서 성 공적인 예후를 보여 이를 보고하고자 한다.

(구강회복응용과학지 2018;34(4):317-23)

주요어: 구강암; 상악골절제술; 텔레스코픽형 이중관 의치; 마찰핀

*교신저자: 조진현

(41940)대구 중구 달구벌대로 2177 경북대학교 치과대학 치과보철학교실

Tel: 053-600-7651 | Fax: 053-427-0778 | E-mail: prosth95@knu.ac. kr

접수일: 2018년 7월 29일 | 수정일: 2018년 8월 23일 | 채택일: 2018년 9월 9일 